\title{
Nuevas noticias sobre el retablo sevillano del Renacimiento. Talla, dorado y pintura de un retablo para el convento de la Santísima Trinidad de Marbella
}

\author{
Antonio Joaquin Santos Márquez \\ Universidad de Sevilla
}

El Renacimiento se puede considerar una de las grandes etapas de la retablística andaluza. Desde principios de la centuria del quinientos, se aprecia una verdadera fiebre en la traza y construcción de estas empresas artísticas, lo cual viene a ratificar la consolidación de una modalidad tipológica que se convertirá en una de las manifestaciones más relevantes de la plástica andaluza durante la Edad Moderna.

En Sevilla, como gran centro político y económico durante el siglo XVI, se fragua una importante escuela artística a partir de este momento, y tendrá en los retablos, uno de sus medios de expresión más creativos, donde además se expondrán las novedades propias del Renacimiento ${ }^{1}$. Sus artistas, locales y foráneos, trabajarán no sólo para el antiguo territorio del Reino de Sevilla, sino también para aquellas otras tierras limítrofes, como las pacenses o las de la Andalucía Oriental, estas últimas ávidas de enriquecer con obras cristianas unas arquitecturas aún con un fuerte sabor islámico. Por ello no es de extrañar que a Sevilla se dirigiesen los diferentes mecenas de estas tierras para encargar sus retablos, de los cuales aún nos queda una buena muestra en los majestuosos ejemplos de la iglesia mayor de Medina Sidonia y de la parroquial de Santa Catalina de Fregenal de la Sierra, obras representativas de la expansión de una labor de entalladura, pintura y dorado que hoy día ha desaparecido en la mayor parte de los casos y cuya existencia conocemos a través de los documentos ${ }^{2}$.

Así pues, no nos ha de extrañar, centrándonos ya en el asunto que nos compete, que instituciones religiosas malagueñas acudiesen a artistas sevillanos para construir los retablos de sus iglesias. Concretamente, nos puede servir de ejemplo la noticia inédita del concierto del retablo de la comunidad monástica de los trinitarios de Marbella, que a través de su casa madre en Sevilla, pudo establecer los vínculos necesarios para que se pudiese llevar a cabo su encargo ${ }^{3}$. Gracias a esta documentación, que es más bien parca en detalles formales pero eficiente para el conocimiento de los artistas que intervienen, los plazos, los costes del mismo y otros aspectos de su creación, podemos hoy día refrendar la vinculación artística existente en estos

* SANTOS MÁRQUEZ, Antonio Joaquín: "Nuevas noticias sobre el retablo sevillano del Renacimiento. Talla, dorado y pintura de un retablo para el convento de la Santísima Trinidad de Marbella", Boletín de Arte $n^{\circ} 28$ Departamento de Historia del Arte, Universidad de Málaga, 2007, págs. 611-617. 
años entre la capital malacitana y la hispalense ${ }^{4}$. La noticia que tenemos del retablo marbellí destinado al cenobio de la Trinidad, del que hoy tan sólo queda parte de la estructura arquitectónica del recinto ${ }^{5}$, es el del concierto de la pintura y dorado del mismo, encargado al pintor de imaginería Diego Fernández el día 2 de enero de $1542^{6}$. La única referencia a su estructura contenida en esta escritura, es la de las medidas expresadas en palmos que, según relata el escribano, eran de diez y seis palmos de largo por doce de ancho, medidas que equivaldrían a 3,35 metros de alto por 2,5 de ancho, datos que nos inducen a pensar que podría tratarse de un retablo mediano, de formato tabernáculo, y que quizás ocupara un lugar secundario dentro del templo7.

La arquitectura en madera y su talla habían sido ya realizadas por el entallador Andrés López del Castillo, sin especificarse si se trataba de un retablo escultórico o pictórico. Desafortunadamente el documento tampoco contribuye mucho en la aclaración de este último punto. Las malas condiciones en las que se conserva el legajo que lo contiene, han hecho que las condiciones, que en su origen y como aparece citado en el texto estaban insertas al mismo, hayan desaparecido, careciendo, por tanto, de los pormenores de la pintura y dorado que debía llevar a cabo el referido pintor.

Mucho más explícito es el documento a la hora de detallar los puntos concernientes a los plazos de entrega y al aspecto económico. Con respecto a lo primero, el trabajo debía ser entregado el día de Pentecostés (Pascua del Espíritu Santo) de este mismo año, por lo tanto, la obra debía estar concluida en unos cinco meses, si

\footnotetext{
1 Sobre el estudio del retablo sevillano del Renacimiento destaca la obra de PALOMERO, J.: El retablo seviIlano del Renacimiento: análisis y evolución (1560-1629). Sevilla, 1983.

2 Sobre la documentación conocida han sido de vital importancia las siguientes obras: LÓPEZ MARTÍNEZ, C.: Retablos y esculturas de traza sevillana. Sevilla, 1928; A.A.V.V.: Documentos Varios. Documentos para la Historia del Arte en Andalucía, t. I, Sevilla, 1927; SANCHO CORBACHO, H.: Arte sevillano de los siglos XVI y XVII. Documentos para la Historia del Arte en Andalucía. T. III, Sevilla, 1931; HERNANDEZ DÍAZ, J. Arte y Artistas del Renacimiento en Sevilla. Documentos para la Historia del Arte en Andalucía, t. VI, Sevilla 1933; Arte hispalense de los siglos XV y XVI. Documentos para la Historia del Arte en Andalucía. Sevilla, 1937. MURO OREJÓN, A.: Pintores y Doradores. Documentos para la Historia del Arte en Andalucía. T. VIII, Sevilla, 1935.

3 En los estudios de documentos vinculados con esta ciudad no existe ninguna referencia al mismo. LLORDÉN, A.: Pintores y doradores malagueños (siglos XV-XIX): ensayo histórico documental. Ávila, 1959; Escultores y entalladores malagueños (siglos XV-XIX): ensayo histórico documental, Ávila, 1966; CABRILLANA, N.: Documentos Notariales de Marbella (1536-1573). Archivo Histórico Provincial de Málaga, Sevilla, 1990.

4 Existen otras referencias conocidas de esta época, como el retablo del convento de los Dominicos de Archidona de 1555, y el del convento de esta misma orden de la capital malagueña, concertado por Pacheco en 1622. LÓPEZ MARTÍNEZ, C.: Retablos y esculturas.... Op. Cit., págs. 90-91; HERNANDEZ DÍAZ, J.: Arte y Artistas..., Op. cit., págs. 75-76.

5 A.A.V.V.: Guía artística de Málaga y su provincia, Sevilla, 2006, t. II, pág. 311.

6 ARCHIVO HISTÓRICO PROVINCIAL DE SEVILLA. Sección Protocolos Notariales de Sevilla (a partir de este momento AHPS. SPNS.): Leg. 9810, oficio 16, lib.1 de 1542, fols. 87 v.-89 v.

7 Hay que tener en cuenta que a estas medidas se le añadía luego la altura de la mesa de altar, siendo las mismas, por ejemplo, que el retablo que realiza Juan Bautista Vázquez el Viejo para la parroquia de Manzanilla en 1567. PALOMERO, J.: El retablo sevillano..., Op. Cit., págs. 73, 176-177.
} 
- Vería Nuevas noticias sobre el retablo sevillano del Renacimiento...

consideramos que esta fecha suele coincidir con los últimos días del mes de mayo y los primeros de junio. El precio establecido era de 9000 maravedíes, los cuales debían de ser pagados en Sevilla, la cuarta parte de los mismos, 6 ducados, se le entregaba en este mismo momento para comenzar la obra, mientras que el resto sería abonado de la siguiente manera: otra cantidad similar cuando terminase la primera cuarta parte del retablo, otra cuando finalizase la mitad del mismo y el resto cuando entregase a la orden trinitaria el trabajo concluido. La obra debía seguir de forma estricta las condiciones referidas so pena de tener que devolver el doble de las pagas entregadas, haciéndose asimismo cargo de las costas generadas en el traslado de las piezas desde el taller de Andrés López hasta su obrador. También se comprometía firmemente a guardar este concierto, ya que si no lo hiciera debía pagar al monasterio marbellí 20000 maravedies, además de todas las cosas, daños y menoscabos que sobre los pleitos surgidos se exigieran.

Para ratificar el convenio, se constituyeron como fiadores del mismo su suegro, el pintor Alonso Pérez, y Antón Sánchez de Guadalupe, igualmente maestro en este oficio, comprometiéndose ambos a realizar la pintura y dorado del retablo si fallase en su empeño el encargado de hacerlo. Finalmente, el teólogo trinitario fray Juan Palomino, prometía también guardar todo lo expresado en el texto, comprometiéndose a pagar los 9000 maravedíes en caso de faltar a esta obligación.

Sobre el protagonista del retablo, hasta el momento, de su vida y producción poco se conoce. Si rastreamos en los documentos publicados, podemos comprobar como existen al menos tres pintores llamados Diego Fernández avecindados en Sevilla durante la primera mitad del siglo XVI, lo que dificulta la identificación del mismo. Tenemos la referencia de un pintor de este mismo nombre en 1504, que claramente nada tiene que ver con el nuestro ${ }^{8}$; otro pintor Diego Fernández, vecino de San Bartolomé, aparece en dos escrituras en 1514 realizando labores de compraventa de mercancías 9 ; y finalmente, el último localizado, en esta ocasión avecindado como el nuestro en la collación de San Vicente, se documenta entre 1522 y 1523 realizando labores de mayordomía en el hospital de los pintores, en 1526 siendo prioste de la cofradía (en todos estas noticias compareciendo junto a Alonso Pérez y a Antón Sánchez de Guadalupe) ${ }^{10}$, y, años más tarde, concretamente el 25 de agosto de 1536, otorgando un poder a Pedro Moreno para que cobrase ciertos maravedíes de una obra pictórica ${ }^{11}$. Ante estos datos, creemos estar en lo cierto al identificar a nuestro pintor con éste último, persona con una posición aventajada dentro de la institución gremial sevillana, y relacionado con los mejores maestros, hechos que le avalan para que los trinitarios sevillanos le recomendasen para este trabajo.

8 En concreto se trata del pintor que en 1504, junto a Diego Martín y Bernal, concierta unas obras de pintura para el bailo de la orden de San Juan. HERNÁNDEZ DÍAZ, J.: Arte hispalense de los siglos XV y XVI..., op. cit., pág. 12.

9 MURO OREJÓN, A.: Pintores y Doradores..., Op. Cit., págs. 32, 34.

10 Ibídem., págs. $6,42,47$.

11 SANCHO CORBACHO, H.: Arte sevillano de los siglos XVI y XVII..., Op. Cit., pág. 18. 
Con el entallador Andrés López del Castillo tenemos mejor fortuna, ya que el profesor Hernández Díaz dio buena cuenta de su importante producción en varios puntos de la geografía andaluza ${ }^{12}$. Así, para la ermita de Nuestra Señora de los Ángeles de Jimena de la Frontera (Cádiz), concertó un retablo junto al pintor Juan Enríquez el 29 de marzo de 1543, otro para la parroquia de San Pedro de Sevilla, y otro más para la iglesia de San Bartolomé de Cumbres de Abajo (Huelva), ambos en 1557. Estos datos, junto al de Marbella, hacen presuponer que se trataba de un destacado entallador, aunque, por desgracia, no tengamos prueba material que lo refrende.

Algo similar sucede con los otros dos pintores que actúan como fiadores del concierto. De Alonso Pérez (también llamado en algunos documentos Alfonso), se tiene una importante cantidad de referencias escritas sobre su actividad en estos años, destacando los encargos de Sanlúcar la Mayor en 1530 y las obras para el Marqués de Tarifa en 1539, unido a su aparición en varias ocasiones junto al referido Diego Fernández, que dan fe de la vinculación familiar y profesional entre ambos ${ }^{13}$. Mucho más conocida es la carrera artística de Antón Pérez de Guadalupe que, junto a su hermano Pedro, trabaja, desde 1520 y hasta su muerte en 1565, en numerosos encargos provenientes de diversos lugares de Andalucía ${ }^{14}$

No obstante, y como dijimos en un principio, lo más dificultoso es poder determinar cual podría ser la imagen del retablo. Si tenemos en cuenta su fecha y los participantes en la creación, creemos que el trabajo que se le encarga a Diego Fernández es la de policromar, estofar y dorar la labor arquitectónica y escultórica de López del Castillo, sobre todo ante las noticias referentes a sus trabajos aludidos, y siendo además común que este tipo de conciertos con pintores se destinasen a rematar la obra escultórica de otro. También si nos detenemos a valorar el precio de esta labor pictórica, 9000 maravedíes, que se corresponderían con un total de 24 ducados, claramente hace decantarnos por esta misma opción, ya que se aleja en mucho de los costes estipulados para los retablos pictóricos ${ }^{15}$. Desgraciadamente nada conocemos de su iconografía, que posiblemente sería trinitaria.

Por lo tanto, y a la vista de todas estas informaciones e interpretaciones, tan sólo nos queda añadir que la obra debió presentar ya una estética renacentista, si nos atenemos igualmente a los retablos coetáneos antes referidos, y que, sin duda, debió estar colocada en su sitio para su bendición después de la referida Pascual del Espíritu Santo del año de 1542, no teniéndose constancia documental de lo contrario.

12 HERNANDEZ DÍAZ, J.: Arte y Artistas del Renacimiento..., Op. Cit., págs. 54-58.

13 HERNANDEZ DÍAZ, J.: Arte hispalense de los siglos XV y XVI..., Op. Cit., págs. 24-27.

14 VALVERDE MADRID, J.: "Pintura sevillana en la primera mitad del siglo XVl", Archivo Hispalense, $\mathrm{n}^{\circ} 75$ 1956, pág. 126.

15 Por ejemplo, por la policromía y dorado del retablo de la Granada de la parroquial de San Lorenzo de Sevilla se le pagaron 38 ducados a Esturmio y a Antón Pérez en 1555, y en el de Nuestra Señora de la iglesia de Santa Marina de esta misma ciudad fueron 7000 maravedíes los que le dieron por estas labores a Andrés Morín en 1556. PALOMERO, J.: El retablo sevillano..., Op. Cit., págs. 146-147. 
Q Varia Nuevas noticias sobre el retablo sevillano del Renacimiento...

\section{APÉNDICE DOCUMENTAL}

Archivo Histórico Provincial de Sevilla. Sección de Protocolos Notariales de Sevilla. Legajo 9810 , oficio 16 , libro $1^{\circ}$ de 1542 , fols. 87 vuelto- 89 vuelto.

"Pacto e postura.

Sepan cuantos esta carta vieren como yo Diego Fernández pintor de imaginería vecino que soy desta ciudad de Sevilla en la collación de Santa María otorgo y conozco que hago pacto e postura e conveniencia sosegada con vos el muy reverendo señor fray Juan Palomino maestro en Santa Teología ministro en el monasterio de la Santísima Trinidad extramuros que esta del presente en esta manera que yo me obligo de pintar e dorar para el monasterio de la Santísima Trinidad de la ciudad de Marbella que Andrés López entallador tiene a cargo un retablo de diez y seis paños de largo e doce de ancho poco más o menos con las condiciones y en la manera y forma siguiente.

Estas son las condiciones que a de tener el retablo que son las que están entre las hojas de este registro.

La cual dicha obra de pintura e dorado del dicho retablo otorgo e me obligo de comenzar a facer desde oy día que esta carta es fecha y otorgada e lo dar fecho e acabado en perfección conforme a las dichas condiciones de susodicho declaradas y a vista de maestros pintores oficiales del dicho oficio que de ello sepan e de lo dar fecho e acabado desde oy día que esta carta es fecha e otorgada hasta el día de pascua del espíritu santo primera que va de este presente año en que estamos de la fecha de esta carta so la pena que en esta carta ser costada por precio toda la dicha obra e pinturas e dorado de suso declarada en la manera que dicho es de nueve mil maravedíes los cuales me aveis de dar e pagar aquí en la dicha ciudad de Sevilla sin pleito e sin contienda alguna en esta manera la cuarta parte de los dichos nueve mil maravedíes que son seis ducados luego para comenzar la dicha obra los cuales yo de vos el dicho señor ministro recibi principalmente e con efecto en presencia del escribano público de los testigos en reales de plata en los valieron e montaron que son en mi poder de que me doy de vos por bien contento e pagado a mi voluntad e fecha la cuarta parte del dicho retablo otra cuarta e estando fecha la mitad del dicho retablo la otra quarta parte en acabándolo de hacer y acabado conforme a las dichas condiciones y a vista de los dichos oficiales pintores que de ello sepan so pena del doblo de cada paga e que yo el dicho Diego Fernández sea obligado a llevar el dicho retablo a mi costa desde casa del dicho Andrés López entallador para lo pintar e dorar como dicho es en esta manera otorgo e prometo e me obligo de hacer cumplir lo susodicho en la manera que dicha es e de me non quitar esta dicha conveniencia e iguala e de tener e guardar e cumplir e haber por firme e valedero todo lo que esta carta contenido e cada cosa de ello e de no ir ni venir con- 
tra ello ni contra parte de ella yo ni otra por mi so pena de dar e pagar al dicho monasterio de la santísima trinidad de la ciudad de marbella a vos el dicho señor ministro en su nombre veinte mil maravedies con todas las costas e daños e menoscabos que sobre ello se le recrecieren e la dicha pena pagada o non pagada con todo lo en esta carta contenido e cada cosa de ello vala e era firme en todo e por todo segun que es se contiene e por que mas cierto e seguro es yo vos el dicho señor ministro hare e cumplire lo susodicho vos doy conmigo por mis fiadores de mancomun en la dicha razon a Alonso Pérez pintor mi suegro vecino de esta dicha ciudad de Sevilla en la collación de San Martín y a Antón Sánchez de Guadalupe pintor vecino de esta ciudad de Sevilla en la collación de San Salvador que estan presente en tal manera que yo le saque a paz e a salvo de esta fianza e si ellos o alguno de ellos o otro por ellos por mi alguna cosa pagare o costas o daños se le recrecieren que no se lo pague como principal obligado e nos los dichos Alonso Pérez e Antón Sánchez de Guadalupe que a todo esto que dicho es presentes somos como sus fiadores nos todos tres de mancomun e a vos de uno e cada uno de nos por el todo renunciando como expresamente renunciamos a la utentores duobus (...) y es que hablaren en razon de la mancomunidad como en ellas se contiene otorgamos e nos obligamos de hacer dicho retablo pintura y dorado con las condiciones en el termino según y en la manera que es dicho y declarado por firme todo lo en esta carta contenido e cada cosa de sobre ello e de no ir contra ello ni contra parte de ello sobre dicha pena de ellos dichos veinte mil maravedíes para el dicho monasterio de la Santísima Trinidad de la dicha ciudad de Marbella contadas las costas e daños e menoscabos que sobre ello se le recrecieren e vos el dicho fray Juan Palomino ministro del dicho monasterio de la Santísima Trinidad de esta dicha ciudad de Sevilla que a todo esto que dicho es presente soy otorgo y conozco que recibo en mi este dicho contrato de conveniencia que vos el dicho Diego Fernández pintor conmigo faceis e poneis de pintar el dicho retablo de suso declarado para el dicho monasterio de la Santísima Trinidad de la dicha ciudad de Marbella por el dicho precio de los dichos nueve mil maravedíes de que vos di e pague luego adelantados la cuarta parte de ellos e con las dichas condiciones de suso declaradas e otorgo e me obligo de vos dar e pagar las dichas tres cuartas partes restantes de los dichos nueve mil maravedíes e a los dichos plazos de suso declarados so la dicha pena del doblo e de me nos quitar de esta dicha conveniencia e igualar de tener e guardar cumplir e aver por firme valedero todo lo en esta carta contenido e cada cosa de ello e de no ir ni venir contra ello ni contra parte de ello y sola dicha pena de los dichos veinte mil maravedíes para vos el dicho Diego Fernández con todas las costas e daños e menoscabos que sobre ello se vos recrecieren a demas de esto si nos ambas las dichas partes e cada una de nos asi no los pagaremos e tovieremos e guardaremos cumpliremos como dicho es por esta carta damos e otorgamos 
libres llenero e cumplido poder a todos cualesquier alcaldes e jueces e justicias de esta dicha ciudad de Sevilla como de todas las otras ciudades villas e lugares de los reinos e señoríos de su majestad de cualquier fuero e jurisdicción queriendo que quien o ante quienes por carta pareciere e de ellas de lo en ella contenido fuere pedido e demandado cumplimiento de justicias para que por todo e los remedios e rigores derecho nos contravienen cumplimiento apremien a lo ansi pagar e tener e guardar e cumplir como dicho es ansi por via de ejecución uno en otra cualquier manera bien ansi e atan cumplidamente como si todo esto que dicho es fuesen cosa juzgada pasada en pleito por de manera e por respuesta e fuese sobre ello dada sentencia definitiva e la tal sentencia fuese consentida de las partes en juicio sobre lo cual renunciamos toda apelación (...) e vista suplicación agravio e maldad e todas e cualesquier leyes fueros e derechos e ordenamientos reales economicos civiles e municipales ansi en general como en especial e todas cartas e cindes e privilegios de rey o de reina o de principal o de infante o arzobispado o de otros señores o señoras poderosas cualesquier que eran ganadas e por quantas e todas vuestras razones ejecuciones e definiciones que por ello espongamos con leguemos que no convalan ni aprovechen en esta juridision fuera de leyes principal e cual dar se renunciamos la ley del derecho en que dice (...) renunciación vala e para lo asi parecer guardar cumplir como dicho todo esto es dichos Diego Fernández Alonso Pérez e Antón Sánchez obligamos nuestras personas e bienes muebles e raices avidos e por haber e yo el dicho fray Juan Palomino obligo los bienes y rentas de este dicho monasterio de la Santísima Trinidad de esta dicha ciudad de Sevilla muebles e raices espirituales e temporales avidos e por haber fecha la carta en Sevilla estando en el dicho monasterio de la Santísima Trinidad extramuros de la dicha ciudad de Sevilla lunes dos días del mes de enero año del nacimiento de Nuestro Señor Salvador Jesucristo de mil e quinientos e cuarenta e dos años y el dicho señor fray Juan Palomino ministro e los dichos Diego Fernández e Alonso Pérez e Antón Sanchez lo firmaron de sus nombres que fue registro testigos que fueron presentes a lo que dicho es Juan Gutiérrez e Francisco Carvajal escribanos de Sevilla.

Pacto e postura que otorgo Diego Fernández pintor con el padre ministro de la Santísima Trinidad de dorar e pintar un retablo por precio de nueve mil maravedíes fiadores Alonso Pérez e Antón Sánchez de Guadalupe de mancomun.

(Firmas) Fr. Joan Palomino, Diego Fernández, Antón Sánchez, Alonso Pérez, Juan Sánchez Reinoso escribano público de Sevilla, Francisco de Carvajal escribano de Sevilla, Juan Gutiérrez escribano de Sevilla." 